\title{
Estudo sobre os acidentes e o conhecimento como mecanismo de prevenção: compreendendo o cuidar e educar na educação infantil.
}

Alexandre Freitas Marchiori

Crianças estão muito sujeitas aos mais diversos tipos de acidentes e o controle disso é uma questão de saúde pública, tão alto é o número de vidas abreviadas $e$ invalidadas. Prevenir os acidentes infantis é uma questão de informação e de atenção de pais, educadores e de todos aqueles que zelam pela infância (Bibliomed, 2002).

\section{Introdução}

Conforme Filócomo et al (2002), faz-se necessário modificar o conceito de que os acidentes estão relacionados com casualidade e imprevisibilidade. As autoras apresentam um conceito de acidente:

Seria considerado como "injúria não intencional" causada pela transmissão rápida de um tipo de energia dinâmica, térmica ou química de um corpo a outro ocasionando danos e até a morte e, desta forma, podem ser evitados e controlados.

Seguem na discussão, avançando na dissecação do termo. Descrevem que se tem usado tal conceito para descrever a epidemiologia dos acidentes adotando o modelo agente-hospedeiro-ambiente. $\mathrm{O}$ agente seria a forma de energia que lesa os tecidos orgânicos; o hospedeiro seria a criança onde identificaríamos o risco de acidente de acordo com o seu estágio de desenvolvimento e o ambiente incluiria a situação física e psicossocial na qual ocorre o acidente. O conhecimento desta tríade fornece subsídios para direcionar ações de prevenção e identificar os grupos de maior risco (FILÓCOMO et al, 2002).

Segundo artigo publicado no site da Procuradoria Geral da República/Ministério Público Federal, os acidentes na infância ocorrem com muita frequiência. Alega-se que 
as crianças normalmente não conseguem prever o que pode acontecer e só adquire esta "responsabilidade" por volta dos sete anos de idade. $\mathrm{O}$ artigo defende que cabe aos adultos tentar evitar os riscos de acidentes. Esses, têm o ambiente doméstico como local de maior incidência (90\%) entre choques, quedas, asfixias freqüentes entre 0 e 6 anos.

Contribui com esta discussão alguns achados da pesquisa realizada pela ex-chefe de enfermagem Shirley Rangel Gomes, do Hospital São Camilo, de São Paulo. Segundo a pesquisadora, o maior índice de acidentes observados no Pronto Socorro do Hospital ocorreu na faixa etária de 8 a 12 anos $(31,4 \%)$. Concluiu-se que, por esta faixa etária corresponder à fase escolar, a criança desenvolve atividades independentes do seu círculo familiar, na escola, entre os amigos e praticando esportes, o que a expõe a maiores oportunidades de acidentes.

Sobre as crianças abordadas nesta pesquisa, os achados permitem compreender a dinâmica que envolve o cuidar/educar na Educação Infantil. A autora apresenta que a segunda faixa etária mais atingida corresponde à etapa dos 2 aos 4 anos incompletos, ou seja, $17,8 \%$ do universo pesquisado. Nesta idade, a criança caminha sozinha, sua curiosidade é inata ao seu desenvolvimento e o ambiente pode ser propício aos acidentes, explica a enfermeira. Entre os 4 e 6 anos incompletos, correspondentes à fase pré-escolar, a criança dispõe-se a realizar tarefas ainda inadequadas ao seu desenvolvimento físico e intelectual, o que pode levar a acidentes. A enfermeira concluiu que as outras faixas etárias são importantes, mas representam índices pouco menores, embora com o mesmo risco de morbidade.

Um dado alarmante revelado pela pesquisa da enfermeira, é que em 62,3\% dos casos atendidos no Hospital, o local em que se deram os acidentes envolvendo crianças foi sua própria casa ou a de parentes. Com um índice bem mais reduzido, a escola desponta como o segundo palco dos acidentes infantis: $15,7 \%$, seguida da rua, onde ocorrem $11,1 \%$ dos casos. "A grande maioria dos acidentes acontece na presença da 
mãe", diz a enfermeira, que chama a atenção para o fato de que o comportamento das crianças muda muito na presença materna, muitas vezes visando chamar a atenção de uma mãe em geral também ocupada com outros afazeres domésticos (Bibliomed, 2002).

Nesse mesmo artigo, publicado no site <boasaude.uol.com.br>, o Dr. Manuel Naves, pediatra do Pronto Socorro do HRT (Hospital Regional de Taguatinga, de Minas Gerais) explica que as crianças de 1 a 2 anos são muito ativas e têm necessidade de investigar, escalando, abrindo portas e gavetas, retirando coisas de armários e brincando com água. Como medida preventiva, propõe observar de perto as crianças desta idade, pois elas estão muito interessadas no que estão fazendo e tem pouca consciência dos perigos que podem estar correndo. Nesta idade são comuns as quedas e os cortes, provenientes de atividades tais como arremessar e chutar bola, correr, pular e pedalar um velocípede. Há entendimento da parte delas, mas ainda não sabem o que é perigoso, necessitando de proteção, supervisão e disciplina firme.

Os dois especialistas/pesquisadores descrevem que com esta faixa etária (3 a 5 anos), a criança explora a vizinhança, corre, escala, anda com velocípede, aprende a andar de bicicleta, brinca com outras crianças. Ensinam ainda que nesta fase elas sobem em árvores, ficam em pé em balanços, brincam com mais violência com os brinquedos, bolas pesadas, fósforos e isqueiros, além de experimentarem remédios. Nesta fase, as crianças podem aceitar e responder aos ensinamentos, porém, elas ainda necessitam de proteção. Os sujeitos de seis anos explodem em energia e constante movimento. Com um tempo de concentração breve, eles iniciam novas tarefas que não conseguem concluir, são autoritários e sensíveis. Aos sete anos, elas ficam mais quietas que aos seis, mas são mais criativas e gostam de aventuras.

A prevenção dos acidentes na infância pode e deve ser instituída. O termo "acidente" implica a sua imprevisibilidade, e embora seja certo que as lesões não tenham maior probabilidade de ocorrer do que as doenças, estar atento para as situações 
de risco pode evitar perdas irreparáveis. A palavra de ordem é manter uma atenção redobrada e, no caso de acontecer algum acidente, além do socorro imediato, procure sempre um hospital ou centro de saúde (BIBLIOMED, 2002).

Conforme Carvalho (1997), quando aborda os acidentes infantis, relata que as crianças apresentam uma limitação física, sensorial, psicomotora e cognitiva, que só serão desenvolvidas com o tempo. Tal afirmação é respaldada nos estudos de Piaget, relativos à maturação biológica. Segundo a autora, a vigilância, a atenção e a supervisão constantes são essenciais, à medida que a criança adquire maiores habilidades locomotoras e manipulativas, que são acompanhadas pela curiosidade em relação ao ambiente. Crianças de 2 a 6 anos correm, pulam e já começam a entender, mas ainda não sabem o que é perigoso. Elas precisam de proteção, supervisão e disciplina firme. A partir de 3 anos, já entendem, mas ainda precisam de proteção. Encerra seu artigo alegando que a prevenção de acidentes requer proteção e educação.

Filócomo et al (2002), quando na discussão dos dados de sua pesquisa, demonstram que em relação aos tipos de acidentes, a maioria foi decorrente de queda (46,9\%). Na análise primária dos dados, verificou-se que 60,9\% foram decorrentes de queda da própria altura e 39,1\% de outros lugares: cama $(13,5 \%)$, bicicleta $(12,3 \%)$, escada $(9,2 \%)$, cadeira $(6,1 \%)$, muro $(6,1 \%)$ e outros. Logo a seguir aparecem com maior freqüência as contusões $(28,4 \%)$ e ferimentos $(9,7 \%)$. As autoras apresentam uma outra pesquisa que ratifica os resultados, onde dados semelhantes foram encontrados em estudo realizado na cidade de Ribeirão Preto, na qual 46,92\% dos acidentes foram decorrentes de queda, seguidos pelas contusões $(15,38 \%)$ e cortes $(11,92 \%)$.

Seguindo na discussão dos dados, as autoras verificaram também que a queda foi o tipo mais comum de acidente encontrado na faixa etária de menores de 1 ano e entre 1 a 3 anos. Isto se justifica pela fase de maturação motora, cognitiva e psicossocial que se encontram estas crianças, aprendendo a conhecer os seus limites e adaptando-se ao 
meio. Ainda em relação às quedas, estas permanecem em níveis elevados também em crianças acima de 4 anos, evento este relacionado provavelmente as atividades de lazer e esportes, próprias desta faixa etária, destacando-se jogos, bicicleta, patins e outros.

Outro dado importante na pesquisa corresponde à presença dos pais na hora do acidente. Da amostra estudada, em 43,4\% dos casos a mãe ou o pai estavam presentes no momento do acidente, em $22,2 \%$ amigos, em $8,3 \%$ a professora e em $4,3 \%$ casos a criança estava sozinha. Isso indica que a presença de um adulto ou pessoa responsável no local onde as crianças brincam não garante que os acidentes deixem de acontecer. É claro que outras circunstâncias interferem no processo ou no desenvolvimento dos fatos que antecedem ou acompanham a ocorrência.

Quanto ao local do acidente, as autoras descreveram o seguinte quadro: $44,8 \%$ ocorrências em casa; $17,7 \%$ na escola; $7,1 \%$ em via pública; $6,9 \%$ em locais de lazer e $1,8 \%$ em outros lugares. Descrevem também que em outros estudos semelhantes demonstrou que a maioria dos acidentes ocorre em casa $(79,2 \%)$, seguidos de locais públicos $(11,7 \%)$ e apenas 5,8\% aconteceram na escola (Filócomo et al, 2002).

Em suas considerações finais, as autoras indicam algumas medidas que podem clarear os rumos da prevenção de acidentes, em especial:

Acreditamos que a redução da incidência de acidentes na infância pode ser alcançada mediante estudos regionalizados e com a implantação de programas de prevenção específicos. Um dos pilares para a redução desta incidência esta pautada na educação, a qual requer a mobilização de vários segmentos da população, a fim de assegurar às crianças e famílias o provimento de informações e tratamentos necessários que minimizem esta problemática (FILÓCOMO et al, 2002).

Esta fala indica um conhecimento regionalizado, ou seja, para uma população específica, uma comunidade com características culturais, sociais e ambientais distintas. Entretanto, as similaridades podem ser observadas e servir de parâmetro para proporcionar intervenções de qualidade, objetivando a redução das ocorrências e o 
cuidado efetivo das crianças.

\section{Problematização}

Diante das discussões e a constatação de que acidentes acontecem em qualquer lugar e hora e a simples presença de um adulto não garante que as crianças estão livres de qualquer ameaça à sua integridade física, o artigo permite compreender os mecanismos ou circunstâncias que envolvem os alunos na rotina dos Centros Municipais. Contribui, também, com a discussão sobre os serviços prestados nesses espaços educacionais, que, ainda, são vistos como instituições de cuidado/guarda e voltados apenas para a proteção dos pequenos. O termo assistencialista é compreendido como o serviço de cuidado dedicado às crianças nas creches. A Rede Municipal de Vitória vem propondo uma nova forma de intervenção, assegurando ao aluno um processo educacional, assumindo uma linguagem lúdica e articulada com o sistema educacional, regido pela LDB e outras normas/decretos municipais ou instâncias superiores - MEC.

O objeto de estudo "O livro de registro de ocorrências de pais e alunos do CMEI Sinclair Phillips" assume algumas funções que merecem ser mencionadas neste artigo. Há uma resistência interna relativa à forma que os fatos são conduzidos e o questionamento da postura do profissional ante ao registro e o confronto com a família. Alguns professores entendem a necessidade de existir um documento que possibilite ser revisitado sempre que sua fala estiver sendo negada. Existem outros que se recusam a aceitar a sua existência, pois acreditam que isso pode e será usado para prejudicar, de alguma forma, sua carreira e criar um estigma negativo a seu respeito. Os pedagogos entendem como necessário e um instrumento de defesa dos professores e demais profissionais envolvidos na educação dos pequenos. Tais apontamentos são percebidos empiricamente, mediante observação do cotidiano escolar e conversas informais quando surge um fato relativo ao registro ou utilização do livro. 
Um ponto importante corresponde ao perfil das crianças atendidas no CMEI e sua relação com os acidentes. O desenvolvimento cognitivo/motor interfere na interação da criança com o ambiente e, também, com os colegas. Isso é um fator importante para leitura dos dados e também um mecanismo de prevenção. Suas experiências pregressas interferem na forma de se expressar corporalmente, indicando uma autonomia vivenciada nos locais externos à escola. Essa liberdade pode colocar em risco sua integridade física, pois os limites impostos pelo professor(a) talvez não sejam interpretados como cuidado, mas sim impossibilidade de se locomover/explorar o ambiente ou objeto a ser manipulado.

Outro aspecto a ser considerado é a presença de um adulto ou responsável no período de permanência da criança na escola. A probabilidade de acidente é confirmada por algumas pesquisas (citadas neste artigo) proveniente da confiança de que a criança está sobre o olhar/cuidados deste, entretanto, a suposta segurança oferecida será comprometida por uma distração ou conversa com outros sujeitos, inclusive alunos que se aproximam e relatam algum fato. $\mathrm{O}$ acidente pode ocorrer na presença dos pais, fato que é confirmado em alguns estudos ou pesquisas (Filócomo et al, Bibliomed).

Destaca-se ainda neste quadro de acidentes o quantitativo de alunos por sala/aula (até 25 alunos). Trata-se de um fator que deve ser considerado como dificultador na atenção oferecida às crianças. Não é uma desculpa para justificar alguma negligência, mas a necessidade de uma segunda pessoa para "redobrar" a atenção despendida aos pequenos.

Diante do exposto, segue-se uma discussão sobre alguns desses fatores e a pesquisa desenvolvida aqui neste artigo. Visa contribuir com o avanço na qualidade do serviço educacional oferecido, compreender esses sujeitos nas suas múltiplas linguagens e utilizar o conhecimento como ferramenta de controle e prevenção de acidentes. 


\section{Objetivos}

O presente artigo busca, em linhas gerais, entender a questão do cuidar e educar na educação infantil. Seus desdobramentos estão compreendidos em:

1. Identificar as causas de acidentes e as circunstâncias da ocorrência;

2. Identificar o local do fato e o turno que há maior incidência;

3. Averiguar se houve aumento no número de acidentes com a entrada da educação física no CMEI;

4. Descrever as atitudes/procedimentos adotados após o acidente;.

5. Analisar a postura dos pais após os ocorridos, referente ao serviço/ensino no CMEI;

6. Identificar a faixa etária com maior índice de ocorrências.

\section{Metodologia}

O presente estudo assume característica quantitativa, tipo exploratório. Trata-se de uma análise documental, sendo o objeto de estudo as anotações no livro de registros destinado às ocorrências de alunos e pais do CMEI "SP", compreendendo o período de $2005\left(1^{\circ}\right.$ registro em 09/03/2005) a 2008 (último registro em 07/10/2008).

A população corresponde ao quantitativo de, aproximadamente, 1600 alunos, visto que são 04 (quatro) anos de anotações, sendo a média de 400 alunos anualmente matriculados no centro municipal. Como amostra, serão contatos apenas os casos registrados que caracterizam o objeto de estudo (acidentes).

Os dados foram quantificados numa planilha MS Excel e analisados mediante comparação com outras pesquisas do gênero e, também, algumas recomendações de autoridades ou instituições que descrevem os cuidados. Utilizaram-se como referência para análise as indicações de procedimentos de prevenção de acidentes e atitudes 
exigidas após a ocorrência de trauma ou lesões.

\section{Dados coletados e Análise preliminar}

Existe a confirmação de que muitos casos não foram registrados devido a circunstâncias adversas ou por se tratar de acidentes de menor gravidade (avaliado assim pela professora/pedagoga ou responsável legal pela criança). Para tanto, existe uma prática de se colocar copos pequenos para gelar com o objetivo de atender à demanda de quedas ou traumas menores proveniente de choques com objetos ou outro colega. Normalmente, o procedimento inicial é tratar todos os casos com cautela e, recomenda-se, ter a avaliação de um profissional da saúde que examine o quadro geral da criança e prescreva ou determine outros procedimentos, caso necessário.

Tabela 01: quantitativo de ocorrências registradas no período:

\begin{tabular}{|c|c|c|c|c|}
\hline \multicolumn{5}{|c|}{ Quantitativo de ocorrências registradas no período } \\
\hline & \multicolumn{5}{|c|}{ ANO } \\
\hline MESES & 2005 & 2006 & 2007 & 2008 \\
\hline 1 & 0 & 0 & 0 & 0 \\
\hline 2 & 0 & 0 & 20 & 40 \\
\hline 3 & 36 & 19 & 130 & 41 \\
\hline 4 & 39 & 54 & 105 & 23 \\
\hline 5 & 30 & 24 & 93 & 20 \\
\hline 6 & 24 & 3 & 81 & 34 \\
\hline 7 & 12 & 6 & 26 & 30 \\
\hline 8 & 52 & 10 & 42 & 46 \\
\hline 9 & 40 & 8 & 42 & 34 \\
\hline 10 & 17 & 10 & 20 & 8 \\
\hline 11 & 31 & 25 & 34 & 0 \\
\hline 12 & 8 & 5 & 14 & 0 \\
\hline & 289 & 164 & 607 & 276 \\
\hline
\end{tabular}

O mês de janeiro corresponde ao período de férias escolares, por isso não há registro. O mês de fevereiro de 2005 e 2006 também corresponde a férias, fato que se alterou nos anos subseqüentes. A última ocorrência de 2008 aconteceu em 07/10, momento de encerramento do livro. Sendo assim, o estudo estará compreendido nesta fonte de dados. Foram contadas 1336 ocorrências no período entre a abertura e 
encerramento do livro.

Tabela 02: Ocorrências em 2005, dividido por mês e o motivo gerador do registro:

\begin{tabular}{|c|c|c|c|c|c|c|c|c|c|c|c|}
\hline & \multicolumn{10}{|c|}{2005} & \\
\hline Tipos de registros & Mar & $\mathrm{abr}$ & mai & jun & jul & Ago & Set & Out & nov & Dez & TOTAL \\
\hline Saída antes/depois do horário & 3 & 19 & 5 & 4 & 1 & 21 & 11 & 9 & 12 & 3 & 88 \\
\hline Sem carteirinha & 3 & 5 & 1 & 7 & 1 & 5 & 3 & 2 & 2 & 1 & 30 \\
\hline Acidentes & 0 & 1 & 3 & 1 & 0 & 1 & 2 & 0 & 1 & 0 & 9 \\
\hline Reclamações & 4 & 0 & 2 & 1 & 1 & 0 & 6 & 2 & 3 & 1 & 20 \\
\hline Pedidos & 12 & 6 & 10 & 5 & 4 & 16 & 8 & 3 & 5 & 1 & 70 \\
\hline Outros & 0 & 0 & 2 & 1 & 2 & 2 & 3 & 0 & 3 & 2 & 15 \\
\hline Encaminhamento & 2 & $\overline{4}$ & 1 & 3 & 0 & 3 & 1 & 0 & 0 & 0 & 14 \\
\hline Brigas & 2 & 1 & 3 & 0 & 1 & 1 & 4 & 0 & 3 & 0 & 15 \\
\hline Comportamento agressivo & 4 & 3 & 2 & 2 & 0 & 3 & 1 & 1 & 2 & 0 & 18 \\
\hline Retorno de encaminhamento & 1 & 0 & 1 & 0 & 1 & 0 & 1 & 0 & 0 & 0 & 4 \\
\hline Menor buscando irmão & 2 & 0 & 0 & 0 & 1 & 0 & 0 & 0 & 0 & 0 & 3 \\
\hline TOTAL & 33 & 39 & 30 & 24 & 12 & 52 & 40 & 17 & 31 & 8 & 286 \\
\hline
\end{tabular}

Conforme a tabela 02 , o índice de acidentes corresponde a $3.15 \%$ do total registrado, entretanto, se somados aos $5.20 \%$ relativos às brigas perfaz um total de 8.35\%. Esta relação pode ser considerada devido o resultado das agressões. As brigas, segundo registro, deixaram lesões proveniente de queda, arranhões, mordidas e hematomas. Em todos os casos a família foi comunicada do fato e chamada a conversar sobre o ocorrido. É o que se constata nos $6.25 \%$ referentes a comportamento agressivo. Estes registros, em sua maioria, são as conversas com os pais sobre a agressividade, intolerância e desrespeito que alguns alunos, principalmente os envolvidos nas brigas, estavam apresentando em sala de aula, tanto com os colegas, quanto com as professoras. A rotina do CMEI possui a maior carga de registros. Entre saída/entrada de alunos, entrega sem carteira, pedidos, encaminhamentos, retorno, outros, menor buscando irmão e reclamações têm-se um total de $85.31 \%$. 
Tabela 03 - Ocorrências em 2006, dividido por mês e o motivo gerador do registro:

\begin{tabular}{|c|c|c|c|c|c|c|c|c|c|c|c|c|}
\hline & \multicolumn{11}{|c|}{2006} & \\
\hline Tipos de registros & 2 & 3 & 4 & 5 & 6 & 7 & 8 & 9 & 10 & 11 & 12 & TOTAL \\
\hline Saída antes/depois do horário & 0 & 7 & 32 & 5 & 1 & 2 & 3 & 1 & 2 & 16 & 2 & 71 \\
\hline Sem carteirinha & 0 & 0 & 4 & 1 & 0 & 0 & 0 & 0 & 0 & 0 & 0 & 5 \\
\hline Acidentes & 0 & 2 & 1 & 1 & 0 & 0 & 0 & 1 & 2 & 1 & 0 & 8 \\
\hline Reclamações & 0 & 2 & 1 & 2 & 0 & 0 & 0 & 0 & 1 & 0 & 1 & 7 \\
\hline Pedidos & 1 & 6 & 13 & 12 & 2 & 3 & 5 & 3 & 3 & 7 & 1 & 56 \\
\hline outros & 0 & 1 & 2 & 2 & 0 & 0 & 1 & 2 & 1 & 1 & 1 & 11 \\
\hline Encaminhamento & 0 & 0 & 0 & 0 & 0 & 0 & 0 & 0 & 0 & 0 & 0 & 0 \\
\hline brigas & 0 & 0 & 1 & 1 & 0 & 0 & 0 & 0 & 1 & 0 & 0 & 3 \\
\hline comportamento agressivo & 0 & 1 & 0 & 0 & 0 & 1 & 1 & 1 & 0 & 0 & 0 & 4 \\
\hline retorno de encaminhamento & 0 & 0 & 0 & 0 & 0 & 0 & 0 & 0 & 0 & 0 & 0 & 0 \\
\hline menor buscando irmão & 0 & 0 & 0 & 0 & 0 & 0 & 0 & 0 & 0 & 0 & 0 & 0 \\
\hline TOTAL & 1 & 19 & 54 & 24 & 3 & 6 & 10 & 8 & 10 & 25 & 5 & 165 \\
\hline
\end{tabular}

Os números de acidentes continuaram próximos, permanecendo abaixo de 10

(dez) registros. Entretanto, considerando a porcentagem de 5\%, em vez de confirmar o aumento, é mais prudente entender que houve uma quantidade de registro menor em relação ao ano de 2005. As brigas contribuíram com $2 \%$ das ocorrências, acompanhando os relatos de comportamento de agressividade e as conversas com as famílias dos envolvidos. Mais uma vez a rotina do CMEI assume a maior porcentagem, atingindo $93 \%$.

Tabela 04 - Ocorrências em 2007, dividido por mês e o motivo gerador do registro:

\begin{tabular}{|c|c|c|c|c|c|c|c|c|c|c|c|c|}
\hline & \multicolumn{11}{|c|}{2007} & \\
\hline Tipos de registros & 2 & 3 & 4 & 5 & 6 & 7 & 8 & 9 & 10 & 11 & 12 & TOTAL \\
\hline Saída antes/depois do horário & 11 & 42 & 39 & 17 & 10 & 5 & 7 & 13 & 5 & 5 & 1 & 155 \\
\hline Sem carteirinha & 0 & 51 & 51 & 40 & 45 & 2 & 3 & 10 & 4 & 9 & 4 & 219 \\
\hline Acidentes & 1 & 0 & 2 & 3 & 2 & 0 & 1 & 2 & 1 & 1 & 2 & 15 \\
\hline Reclamações & 0 & 2 & 1 & 7 & 5 & 3 & 4 & 1 & 3 & 0 & 0 & 26 \\
\hline Pedidos & 5 & 28 & 9 & 16 & 11 & 8 & 10 & 9 & 4 & 9 & 3 & 112 \\
\hline Outros & 3 & 5 & 1 & 9 & 6 & 6 & 9 & 5 & 1 & 6 & 3 & 54 \\
\hline Encaminhamento & 0 & 1 & 1 & 0 & 1 & 0 & 2 & 0 & & 1 & 1 & 7 \\
\hline Brigas & 0 & 0 & 1 & 1 & 1 & 2 & 2 & 0 & 1 & 0 & 0 & 8 \\
\hline Comportamento agressivo & 0 & 1 & 0 & 0 & 0 & 0 & 4 & 2 & 1 & 3 & 0 & 11 \\
\hline Retorno de encaminhamento & 0 & 0 & 0 & 0 & 0 & 0 & 0 & 0 & & 0 & 0 & 0 \\
\hline Menor buscando irmão & 0 & 0 & 0 & 0 & 0 & 0 & 0 & 0 & & 0 & 0 & 0 \\
\hline TOTAL & 20 & 130 & 105 & 93 & 81 & 26 & 42 & 42 & 20 & 34 & 14 & 607 \\
\hline
\end{tabular}

A tabela 04 indica que os números de acidentes ultrapassaram a unidade, chegando a 15 (quinze) ocorrências. Considerando o quantitativo do ano, perfaz uma 
porcentagem de $2.50 \%$ dos registros. Somando-se as brigas (1.50\%), devido os resultados de lesões ou hematomas, alcança o percentual de $4 \%$ das ocorrências. O comportamento agressivo (2\%) também influencia nos índices, sendo a família convidada a participar na educação dos filhos e tentar solucionar os problemas apresentados em sala ou nos espaços do CMEI. A rotina assume a maior porcentagem, como nos anos anteriores. Um fato que chamou a atenção foram os registros relativos à identificação (carteira fornecida pela escola) dos responsáveis ou portadores das carteirinhas. Devido a exigência de sua apresentação, o volume de registros ultrapassou o esperado. Os atrasos também acompanharam esse aumento. Quanto às reclamações, é importante informar que são computadas tanto as relativas ao comportamento das professoras, dos funcionários, do serviço do CMEI, quanto dos pais ou responsáveis que deixam de atender alguma solicitação da escola.

Tabela 05 - Ocorrências em 2008, dividido por mês e o motivo gerador do registro:

\begin{tabular}{|l|r|r|r|r|r|r|r|r|r|r|c|c|}
\hline \multicolumn{1}{|c|}{ Tipos de registros } & \multicolumn{10}{|c|}{2008} & \multicolumn{1}{c|}{12} & TOTAL \\
\hline Saída antes/depois do horário & 2 & 3 & 4 & 5 & 6 & 7 & 8 & 9 & 10 & 11 & 12 \\
\hline Sem carteirinha & 7 & & 0 & 6 & 1 & 3 & 4 & 1 & 0 & & & 30 \\
\hline Acidentes & 12 & 8 & 6 & 1 & 5 & 7 & 15 & 7 & 2 & & & 63 \\
\hline Reclamações & 3 & 1 & 5 & 1 & 1 & 2 & 0 & 1 & 0 & & & 14 \\
\hline Pedidos & 2 & 4 & 2 & 1 & 5 & 4 & 0 & 5 & 0 & & & 23 \\
\hline Outros & 12 & 10 & 7 & 6 & 7 & 10 & 14 & 7 & 0 & & & 73 \\
\hline Encaminhamento & 3 & 4 & 2 & 4 & 6 & 4 & 5 & 9 & 3 & & & 40 \\
\hline Brigas & 0 & 2 & 1 & 0 & 1 & 0 & 1 & 0 & 1 & & & 6 \\
\hline Comportamento agressivo & 1 & 2 & 0 & 0 & 4 & 0 & 3 & 0 & 1 & & & 11 \\
\hline Retorno de encaminhamento & 0 & 2 & 0 & 1 & 4 & 0 & 4 & 4 & 1 & & & 16 \\
\hline Menor buscando irmão & 0 & 0 & 0 & 0 & 0 & 0 & 0 & 0 & 0 & & & 0 \\
\hline TOTAL & 0 & 0 & 0 & 0 & 0 & 0 & 0 & 0 & 0 & & & 0 \\
\hline
\end{tabular}

Os índices apontam para uma permanência do panorama funcional do CMEI. As

14 ocorrências registradas correspondem a 5\% do total. As brigas somam 4\%, perfazendo $9 \%$ dos fatos. Quanto ao comportamento agressivo (6\%), alguns alunos foram reincidentes e geraram novas ocorrências. A rotina do Centro Municipal manteve o volume de $85 \%$, sendo maioria dos registros no período. 


\section{Resultados}

1) Identificar as causas de acidentes e as circunstâncias da ocorrência:

As quedas são as circunstâncias que tiveram um maior número de registros, perfazendo $42 \%$ das ocorrências. As mordidas (22\%) entraram na relação, entretanto, não caracterizam acidentes. Trata-se de circunstâncias que merecem destaque e análise do quantitativo e seus desdobramentos. Os acidentes provocados por objetos (lápis, bambolê, parafuso, balanço e outros), também atingem $22 \%$ dos registros. Outra circunstância que se destacou corresponde a choque/colisão com colegas. Essa causa de acidentes contribuiu com $11 \%$. As demais correspondem a 3\% dos acidentes (Quadro A).

Segundo relatado no livro, as crianças se acidentaram quando estavam brincando no castelinho, no escorregador, no balanço. Também alguns acidentes ocorreram quando correram, subiram em algum obstáculo/escorregador, ao balançar. Outros tropeçaram na escada ou no próprio colega, desequilíbrio durante um ensaio e em deslocamento para a aula ou outro espaço do CMEI. A maioria dos acidentes ocorreu em sala de aula, em circunstâncias normais e durante a supervisão do (a) professor (a), não havendo indícios de negligência.

2) Identificar o local do fato e o turno que há maior incidência:

As salas de aula correspondem ao local de maior incidência de acidentes (50\%). Tal fato pode ser justificado pelo quantitativo de horas que a criança permanece nesse espaço e as limitações que são impostas ao aluno. Outro ponto que pode ser considerado é o desgaste do profissional em estar monitorando todos os movimentos dos pequenos. O parquinho ou playground (área externa) vem em segundo lugar com $22 \%$ das ocorrências. Se considerarmos este espaço como sala de aula para o professor 
dinamizador, a estatística dos acidentes sobe 9\%, pois foram quatro acidentes registrados tendo este profissional à frente das aulas (Quadro B).

O turno de maior incidência corresponde ao vespertino com $50 \%$ do total dos acidentes, seguido de $33 \%$ dos casos não identificados na ocorrência. O turno matutino ficou com $17 \%$ dos acidentes.

3) Averiguar se houve aumento no número de acidentes com a entrada da educação física no CMEI:

No ano de 2005 não existia a figura do dinamizador na rede municipal, apenas professor de projeto. Em 2006 foi realizado o primeiro concurso para provimento do cargo, entretanto, não contemplou todos os Centros. Tal cargo foi suprido com extensão de professores, onde foi observado o primeiro registro. No ano de 2007 o CMEI recebeu dois professores de Educação Física. Na ocasião, os registros quase dobraram. Saltaram de oito para quinze registros. Em 2008, os números foram mantidos, porém, com um dinamizador de Educação Física e um de Artes (Quadro C).

Os números indicam que houve contribuição dos dinamizadores para o aumento das ocorrências. Entretanto, cabe destacar que o balanço do parquinho não existia em 2005, 2006 e até junho de 2007. Este fato pode explicar o aumento nos acidentes e a exigência de uma adaptação, tanto das crianças, quanto dos professores à frente das aulas. É bem verdade que, possivelmente, os números seriam outros, talvez mais elevados. Com relação à participação desses professores, considerando a dinâmica das aulas e a mobilidade das crianças, no caso, a movimentação exigida nas aulas. Há um aumento potencial dos riscos de acidentes, exigindo uma preocupação e vigilância acentuada durante suas intervenções (Quadro D).

4) Descrever as atitudes/procedimentos adotados após o acidente: 
A conduta adotada pela equipe pedagógica corresponde ao socorro imediato da criança e encaminhamento ao serviço de saúde mais próximo. Neste caso, há um serviço de remoção disponível para a rede municipal, além do já disponibilizado pelos serviços de saúde/segurança (SAMU, Corpo de bombeiro). Após as medidas de acolhimento e primeiros socorros, a família é comunicada e solicitada a comparecer ao CMEI para acompanhar a criança ao atendimento médico. Na ausência do responsável, o professor (a) conduz o aluno e toma as medidas necessárias para cuidar da integridade física e preservar a vida da criança. Há um compromisso da equipe em atender todos os casos com prioridade e responsabilidade, entendendo ser primordial uma avaliação médica e seu encaminhamento ao serviço especializado, salvo quando a família assume os cuidados e avalia que não há necessidade do serviço. Em caso de urgência, o encaminhamento dar-se-á tão logo o serviço especializado se apresente no CMEI.

Nos casos considerados (pelo profissional ou equipe pedagógica) de menor gravidade, o fato é comunicado à família ou responsável que se apresenta no horário de saída das crianças. Tal atitude está respaldada na possibilidade de um agravamento ou sintomas tardios que podem estar relacionados com o acidente.

5) Analisar a postura dos pais após os ocorridos, referente ao serviço/ensino no CMEI:

A família tem atendido os chamados em caso de acidentes, havendo registro de um caso onde não foi possível localizar o responsável. Os pais chegam ao CMEI buscando esclarecimentos sobre a circunstância do acidente e averiguando a gravidade do fato. Na maioria dos casos, aceitaram os argumentos da equipe pedagógica e acataram os procedimentos adotados, inclusive a necessidade de atendimento médico.

Alguns casos não foram comunicados à família ou à pessoa responsável que esteve na escola. Tal procedimento gera um mal estar e um tom de descaso para com a criança. $\mathrm{O}$ atendimento no CMEI é questionado sempre que ocorre um acidente e há um 
clamor para apurar as condições do acidente e os procedimentos adotados para impedir novos acontecimentos. Se há uma rotina de acidentes ou uma seqüência de ocorrências com a mesma criança (apareceram alguns relatos ou reclamações alegando tal fato), a família pede mais rigor na apuração e até o confrontamento, diga-se diálogo, com os responsáveis pela criança quando na escola e a equipe pedagógica.

Mesmo diante de alguns acidentes, o serviço oferecido pela rede municipal é bem aceito e há uma cordialidade no trato dessas questões. O cotidiano escolar sofre alterações rotineiras, provenientes do desgaste dos profissionais, das crianças e outros fatores que interferem no dia-a-dia do CMEI. Isso é considerado para efeitos de se entender o processo educacional e os sujeitos/agentes envolvidos nas circunstâncias em estudo.

6) Identificar a faixa etária com maior índice de ocorrências:

Percebe-se que não há diferença significativa entre as faixas etárias atendidas, salvo o Grupo III, cujo número de registros foi o menor. O grupo VI apresentou a maior incidência, seguido dos grupos II e IV. Não foi considerada a reincidência dos casos, ou seja, se um mesmo aluno teve vários registros. Tampouco foi verificada a concentração dos registros numa faixa etária, tipo zero a três ( 0 a 3 ) ou quatro a seis ( 4 a 6 ). Pode-se considerar a presença de um profissional a mais no atendimento das turmas do Grupo III como fator positivo na prevenção dos acidentes. O estagiário é um diferencial que merece ser observado na dinâmica de sala ou mesmo nas aulas de educação física. Entretanto, a mesma situação não é observada nos Grupos I e II, pois há um efetivo maior nessas salas e o número de ocorrências é acentuado (Quadro E).

\section{Considerações Finais}

$\mathrm{O}$ adulto, independente de sua função no CMEI, assume o risco de acidentes, 
pois a faixa etária atendida é caracterizada pelas descobertas e a inserção da criança na sociedade e suas culturas. Sendo assim, o aluno busca explorar suas potencialidades e, conforme lhe são oferecidas as diferentes linguagens - destaque para artes e educação física - há um aumento dos riscos de quedas ou outras ocorrências. Entretanto, isso não indica uma falha ou deficiência. Devem ser consideradas as situações diferenciadas de aprendizagem e o tipo de linguagem trabalhada com as crianças. Há uma oferta de atividades que se justifica pela concepção de infância que está em construção ${ }^{1}$ e as diretrizes norteadoras na educação infantil.

Entender o cuidar e educar vai além dos números apresentados. Considera-se aqui cada pessoa atingida pelos acidentes, tanto as crianças diretamente envolvidas, quanto seus familiares e professores. Todas as vezes que há um registro, o cotidiano escolar é radicalmente alterado. Exige-se mobilização, acolhimento, cuidados e encaminhamentos. Todas as decisões ficam voltadas para o bem estar do aluno e minimizar os danos provocados pelo acidente. Segue a essas medidas a comunicação com a família e a preocupação em não provocarem inconvenientes ou criar uma circunstância negativa no ambiente escolar.

Os dados confirmam os números de outras pesquisas que apresentam o espaço escolar como contribuinte nas estatísticas dos acidentes. Entretanto, não é possível afastar tais ocorrências, pois as crianças atendidas pelos CMEIs apresentam um desenvolvimento diversificado/não linear. Isso significa dizer que se esperam algumas quedas ou acidentes menores proveniente da exploração e descoberta do mundo por parte dos pequeninos. Todavia, cabe ao responsável observar e prever possíveis locais que coloquem em risco a integridade física das crianças, bem como a movimentação que está acontecendo em volta delas e o espaço disponível para acontecer a intervenção

\footnotetext{
${ }^{1}$ Considero que estamos em uma fase de transição social, onde a infância está sendo encurtada, exigindo novas pesquisas para entender este ser social em desenvolvimento.
} 
pedagógica.

O mapeamento dos locais de acidentes e as circunstâncias envolvidas colaboram para aprimorar o olhar do educador, facilitando a identificação de situações de risco e um trabalho preventivo no cuidado das crianças. O ensino sistematizado acompanha esse ambiente de proteção despendido aos pequenos e, mesmo que haja risco de acidentes, não é prudente privar qualquer aprendizado por conta deste "medo" ou risco iminente $^{2}$. Cabe, sim, um bom planejamento e o apoio de auxiliares para execução das aulas ou atividades pensadas. A prudência deve acompanhar todas as decisões provenientes da avaliação dos riscos e a real necessidade de desenvolver qualquer conteúdo na Educação Infantil.

O trabalho com números não representa desgaste, tampouco provoca reações vivenciadas na prática e no momento do acidente. É impossível esquecer o semblante da criança machucada, a lesão exposta e exigindo socorro urgente, a face dos pais ao contemplarem seus filhos à espera de um acalento, a angústia no pronto socorro e a desconfiança na instituição, nos seus profissionais que falharam no cuidado/guarda de seu tesouro maior. Um pensamento que ronda o cotidiano das aulas é: espero entregar meus alunos inteiros, sem faltar nenhuma parte.

\section{Referências Bibliográficas:}

1 BRASIL. Procuradoria Geral da República/Ministério Público Federal. Acidentes na Infância. Disponível em: http://www.pgr.mpf.gov.br/pgr/saude/textos/acidentes.htm. Acesso em: 13/10/2008.

2 BIBLIOMED, Inc. Prevenção de acidentes Infantis. 2002. Disponível em: http://boasaude.uol.com.br/lib/ShowDoc.cfm?LibDocID=3964\&ReturnCatID=1617.

Acesso em: 23/10/2008.

\footnotetext{
2 Esta abordagem foi defendida por mim em um outro trabalho, onde a necessidade do cuidado precede o educar, mesmo entendendo que tais conceitos estão imbricados e acontecem simultaneamente (Marchiori \& Chiabai, 2007).
} 
3 CARVAlHO, S. D. Principais Acidentes na Infância. Universidade Estadual de Campinas - UNICAMP, 1997. Disponível em: http://www.hospvirt.org.br. Acesso em: $13 / 10 / 2008$.

4 FILÓCOMO, F. R. F. et al. Estudo dos acidentes na infância em um pronto socorro pediátrico. Revista Latino-Americana de Enfermagem, vol.10, no.1, Ribeirão Preto, Jan., 2002.

5 MARCHIORI, A. F. \& CHIABAI, E. M. Saberes Necessários ao Profissional da Educação Infantil: docência em Educação Física. In: I Seminário dos Dinamizadores de Artes e Educação Física da Rede Municipal de Vitória, 2007, Vitória. Anais... Vitória, CEFD/UFES: 2007. 
Quadro A: Causas principais e seus quantitativos discriminados:

\begin{tabular}{|c|c|}
\hline Quantitativo de ocorrências & Causas ou circunstâncias \\
\hline 19 & queda \\
\hline 10 & mordida \\
\hline 7 & arranhão/corte em objetos \\
\hline 5 & colisão/choque com colega \\
\hline 3 & provocado pelo balanço \\
\hline 1 & não identificado \\
\hline 1 & desmaio \\
\hline 46 & Total \\
\hline
\end{tabular}

Quadro B: Local de ocorrências e porcentagem:

\begin{tabular}{|c|c|c|}
\hline Quantitativo & Local & Porcentagem \\
\hline 23 & sala & $50 \%$ \\
\hline 10 & parquinho & $22 \%$ \\
\hline 2 & pátio da frente & $4,5 \%$ \\
\hline 2 & parquinho cxdágua & $4,5 \%$ \\
\hline 1 & pátio refeitório & $2 \%$ \\
\hline 1 & rampa & $2 \%$ \\
\hline 1 & escada & $2 \%$ \\
\hline 6 & não identificado & $13 \%$ \\
\hline 46 & - & $100 \%$ \\
\hline
\end{tabular}

Quadro C - Responsáveis pelas crianças na ocasião do acidente e seu registro:

\begin{tabular}{|r|c|c|c|c|}
\hline & Dinamizador & Profes sor & Estagiária & Sem identificação \\
\hline 2005 & 0 & 6 & 1 & 2 \\
\hline 2006 & 1 & 7 & 0 & 0 \\
\hline 2007 & 5 & 8 & 1 & 1 \\
\hline 2008 & 3 & 10 & 1 & 0 \\
\hline
\end{tabular}

Quadro D - Acidentes registrados quando da responsabilidade do dinamizador:

\begin{tabular}{|c|c|c|c|c|}
\hline data & turma & local & turno & causa \\
\hline 2006 & pré & não revelado & não revelado & des maio \\
\hline 2007 & JI & pátio refeitório & tarde & choque colega \\
\hline 2007 & pré & parquinho & manhã & queda \\
\hline 2007 & JI & parquinho & tarde & balanço \\
\hline 2007 & mat & parquinho & tarde & queda \\
\hline 2007 & pré & parquinho & tarde & queda \\
\hline 2008 & JII & parquinho & tarde & balanço \\
\hline 2008 & mat & sala & tarde & queda \\
\hline 2008 & JII & parquinho & tarde & queda \\
\hline
\end{tabular}


Quadro E - quantitativo de acidentes por grupo ou faixa etária:

\begin{tabular}{|l|c|}
\hline TURMA & TOTAL DE REGISTRO \\
\hline Grupo I ou BI & 6 \\
\hline Grupo II ou BII & 8 \\
\hline Grupo III ou Maternal & 3 \\
\hline Grupo IV ou Jardim I & 8 \\
\hline Grupo V ou Jardim II & 5 \\
\hline Grupo VI ou Pré & 9 \\
\hline Não Identificado & 7 \\
\hline & 46 \\
\hline
\end{tabular}

